\title{
Recent sea ice increase and temperature decrease in the Bering Sea area, Alaska
}

\author{
G. Wendler • L. Chen • B. Moore
}

Received: 1 April 2013 / Accepted: 10 September 2013 /Published online: 22 September 2013

(C) The Author(s) 2013. This article is published with open access at Springerlink.com

\begin{abstract}
We analyzed the sea ice conditions in the Bering Sea for the time period 1979-2012, for which good data based on microwave satellite imagery, being able to look through clouds and darkness, are available. The Bering Sea, west of Alaska, is ice-free in summer, but each winter, an extensive sea ice cover is established, reaching its maximum normally in March. We found a slight increase in ice area over the time period, which is in stark contrast to the significant retreat observed in the Beaufort Sea north of Alaska and the Arctic Ocean as a whole. Possible explanation might be found in the Pacific Decadal Oscillation (PDO), which went from dominantly positive values to more negative values in the last decade. The PDO is related to the sea surface temperature (SST) in the North Pacific, negative values indicated cooler temperatures and cooler SST weakening the semipermanent Aleutian Low. When comparing the circulation pattern obtained from the National Centers for Environmental Prediction/National Center for Atmospheric Research reanalyzed data set for years of heavy ice against light ice years, an additional vectorial northerly wind component could be deduced from the pressure data. Hence, less relatively warm air is advected into the Bering Sea, which becomes of special importance in winter, when solar radiation is at its minimum. Surface observations confirmed these findings. Atmospheric pressure increased in Cold Bay, located close to the center of the semi-permanent Aleutian Low, the $\mathrm{N}-\mathrm{S}$ pressure
\end{abstract}

G. Wendler $(\bowtie) \cdot$ L. Chen $\cdot$ B. Moore

Alaska Climate Research Center, Geophysical Institute,

University of Alaska, Fairbanks, AK 99775, USA

e-mail: gerd@gi.alaska.edu gradient (Nome-Cold Bay) in the Bering Sea decreased, wind speeds of the coastal stations became weakened, and the temperature of coastal stations decreased.

\section{Introduction}

The Bering Sea, located to the west of Alaska lies between the Bering Strait in the north and the Aleutian Island in the south, and Alaska to the east and Siberia to the west (Fig. 1). It is of great economic importance especially for the fishing industry, as about half of the whole US fishing harvest originates from the Bering Sea.

The sea ice conditions are very different between the Bering and Beaufort Seas, the latter one being located north of the northern coast of Alaska (Serreze and Barry 2006; Bridgman and Oliver 2006). The Bering Sea, open to the Pacific Ocean, is ice-free in summer (Zhang and Hibler 1991; Zhang et al. 2010). Danielson et al. (2011) wrote recently a substantial paper on the oceanography of the Bering Sea with 180 citations from which additional literature can be obtained. The icefree season lasts through most of autumn and extensive sea ice, here taken at $10 \%$ of the maximum ice extent in March, is normally not established until late November, and is again reduced to below this value around the beginning of June. In contrast to this, the Beaufort Sea has year-round ice coverage. For the winter season, the ice concentration is around $97 \%$, and at that time of the year only minimal changes occur from year to year. The observed decrease occurred in the melting season, which normally results in the minimal sea ice extent in late August, early September. The length of the melting season as well as the amount of open water has increased, which was shown in a previous study for an area of $200 \mathrm{~km}$ wide and $500 \mathrm{~km}$ along the northern coast of Alaska (Wendler et al. 
Fig. 1 Aerial map of the Bering Sea. The sea ice extents for 10 April 2005, the smallest yearly maximum extent during the study period, and 31 March 2008, the largest ice extent that occurred during the study period

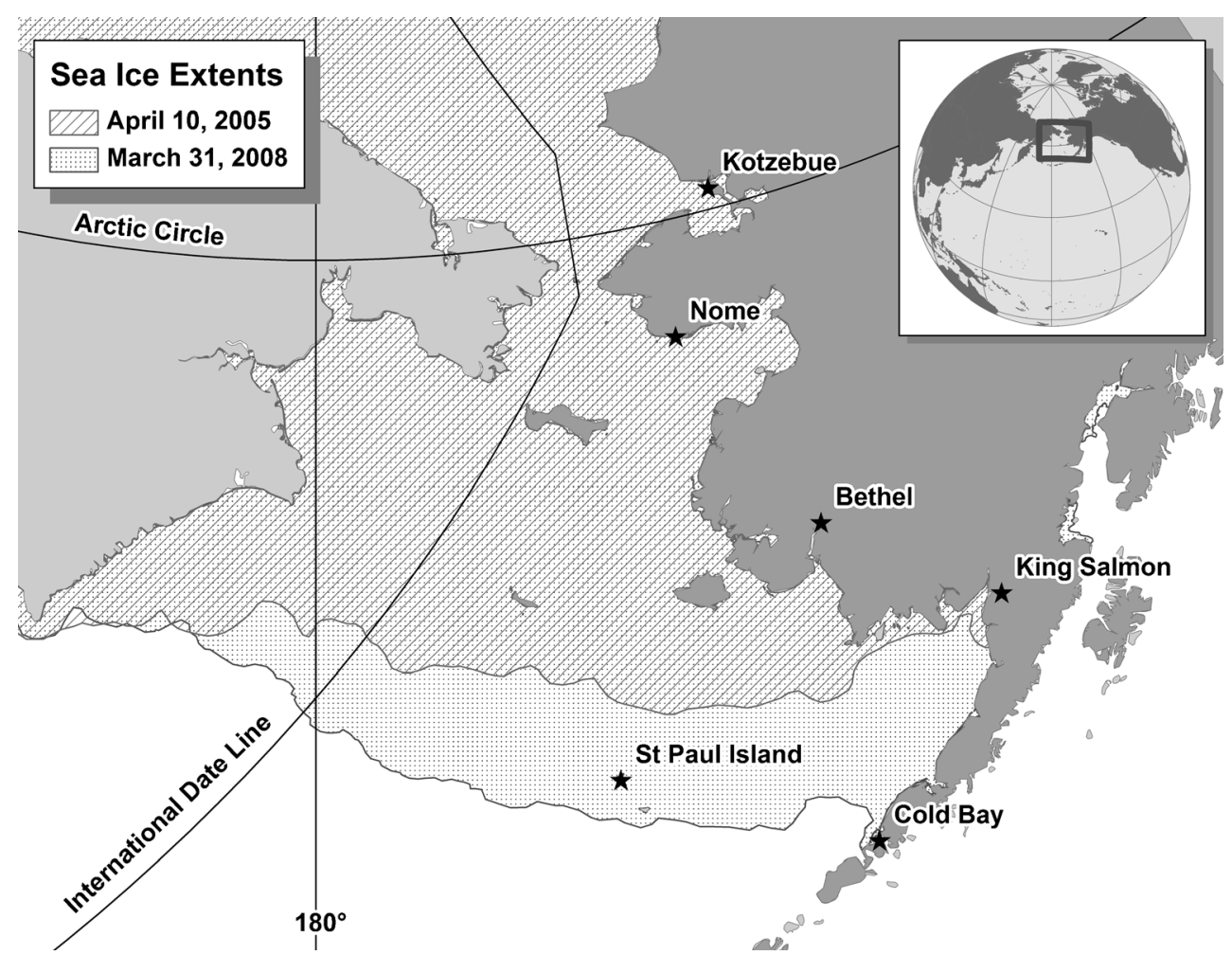

2010). This area is of special interest as Prudhoe Bay, the center of oil activities in Alaska, is located along the coast and offshore activities are impacted strongly by the presence of sea ice. We found a strong decrease in the sea ice concentration. Over a time period of 36 years, the mean annual amount of open water increased from 12 to $32 \%$, as could be deduced from the best linear fit through the time series. This is in agreement with the general strong retreat of ice in the Arctic Ocean and only lately (September 2012), the lowest ice observation with 3.6 million $\mathrm{km}^{2}$ was observed, surpassing the previous record low of 2007. Analyses of sea ice data can be obtained from the National Snow and Ice Data Center in

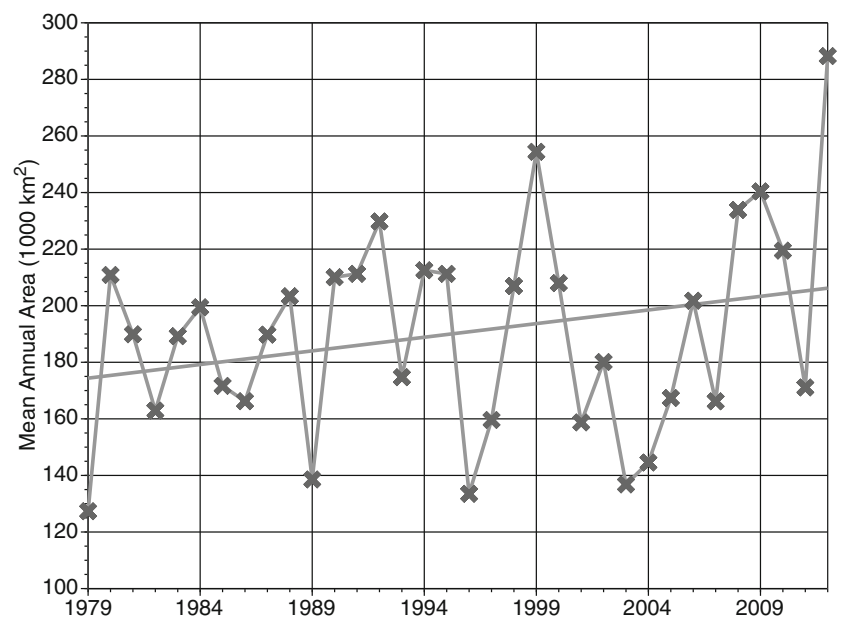

Fig. 2 Mean annual sea ice area for the Bering Sea, 1979-2012
Boulder (Fetterer 2006; Benner 1996), which produce daily maps covering the whole Arctic Ocean (Cavalieri et al. 2006).

\section{Results}

For the Bering Sea, we found a small increase in the mean sea ice concentration for the time period from 1979 to 2012, which was statistical nonsignificant. This is a surprising result, as the sea ice in the Arctic Ocean has generally experienced strong shrinking over the last decades (e.g. Nghiem et al. 2007; Rigor

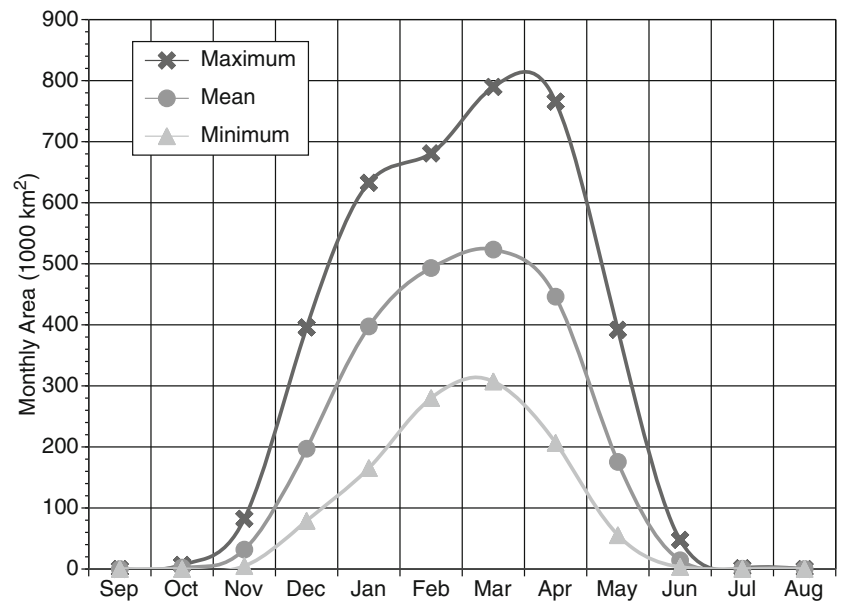

Fig. 3 Annual course of sea ice area of the Bering Sea, mean (1979-2012), maximum, and minimum. The extreme values represent the lowest and highest monthly value of the 34 -year time period 


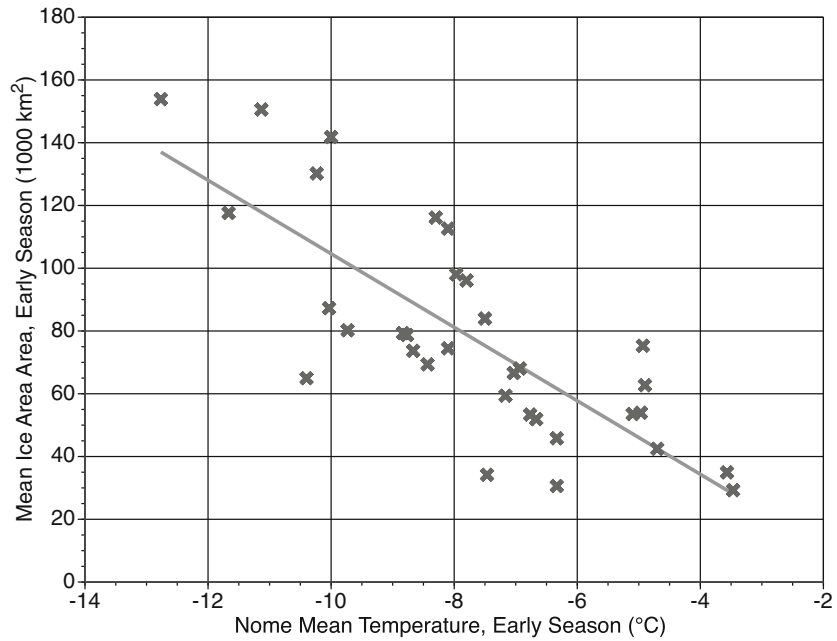

Fig. 4 The relationship between sea ice extent and air temperature for a coastal station (Nome) for the early sea ice season

and Wallace 2004; Serreze et al. 2007; Walsh and Chapman 1990; Walsh et al. 1996; Maslanik et al. 1999; Chapman and Walsh 1993). There are large variations in the average sea ice amount in the Bering Sea from year to year (Fig. 2), from less than $140,000 \mathrm{~km}^{2}$ to more than $280,000 \mathrm{~km}^{2}$. While there are several minima with similar values, there were four pronounced maxima observed in 1992, 1992, 1999, 2009, and 2012.

If we look at the sea ice area, we naturally see a very strong annual variation in the mean annual course. No ice is normally found in July, August, and September (Fig. 3). In October, only very little ice is produced, as the water is still relatively warm from the summer. The new ice production accelerates in November, and becomes large in December and January with more than $150,000 \mathrm{~km}^{2}$ for each month. It starts slowing down in February, and in March the maximum with around $520,000 \mathrm{~km}^{2}$ is reached. Now the decrease starts, which is especially pronounced in May with over $250,000 \mathrm{~km}^{2}$ of ice lost. June continues this trend but

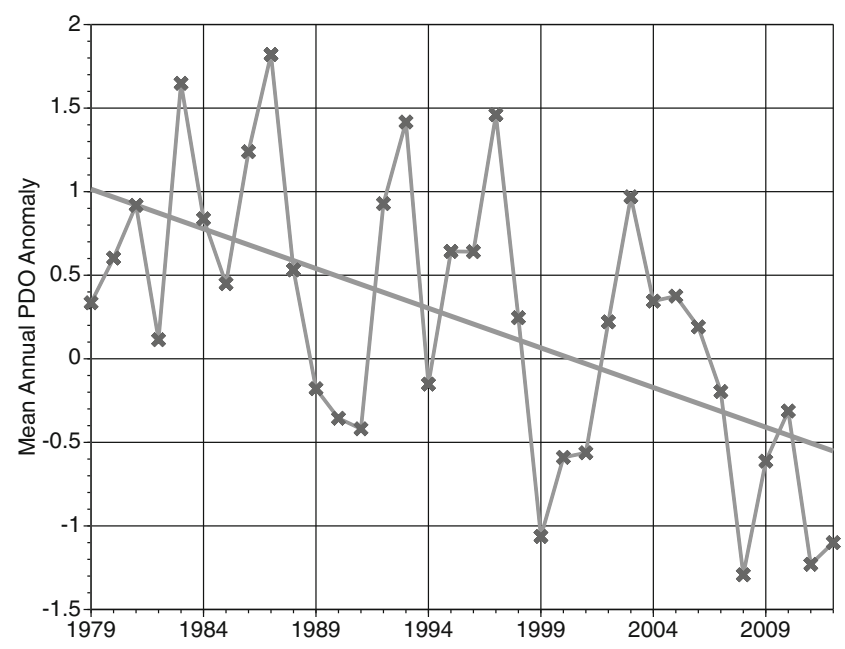

Fig. 5 Time series of the PDO anomalies for the observational period

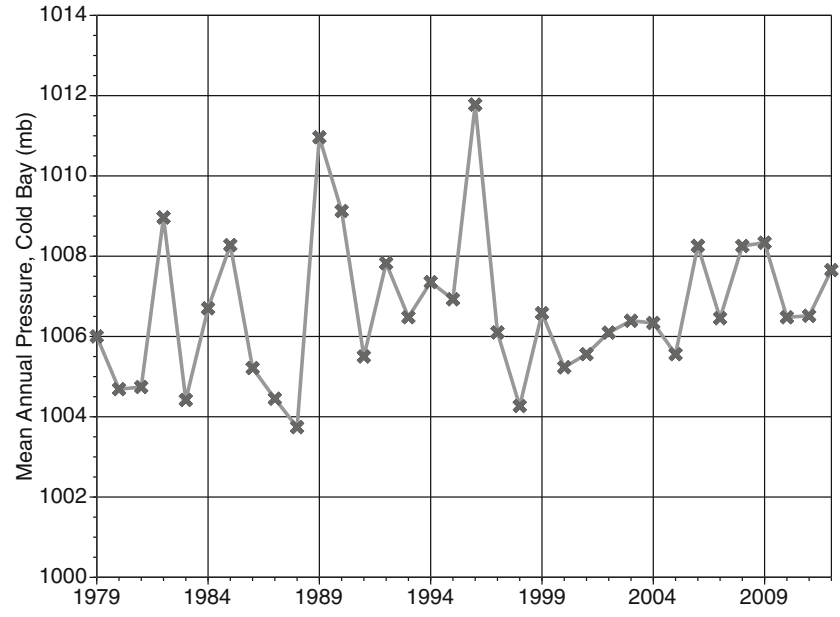

Fig. 6 Time series of the mean annual sea level pressure for Cold Bay for the study period

on a less severe rate, as there is less ice left, and July again becomes the first ice-free month for the Bering Sea.

When we look at the extremes, very large variations can be observed. All three annual courses gave a maximum in ice area during the month of March, with an average value of $523,000 \mathrm{~km}^{2}$. Annual areas for March, however, varied between 307,000 and $790,000 \mathrm{~km}^{2}$. Percentage-wise, the breakup in June is even more extreme. The mean value is around $14,000 \mathrm{~km}^{2}$ and consists of values ranging between no sea ice at all and a maximum monthly coverage of up to $48,000 \mathrm{~km}^{2}$.

The sea ice extent has a strong influence on the temperature of the coastal and island stations. Early in the season, when the ice edge is in the northern part of the Bering Sea, the coastal stations in this area are strongly affected. In Fig. 4, the ice extent in the early ice season (October, November, and December) is plotted against the air temperature of Nome. A high correlation coefficient of 0.62 , significant on the $99 \%$

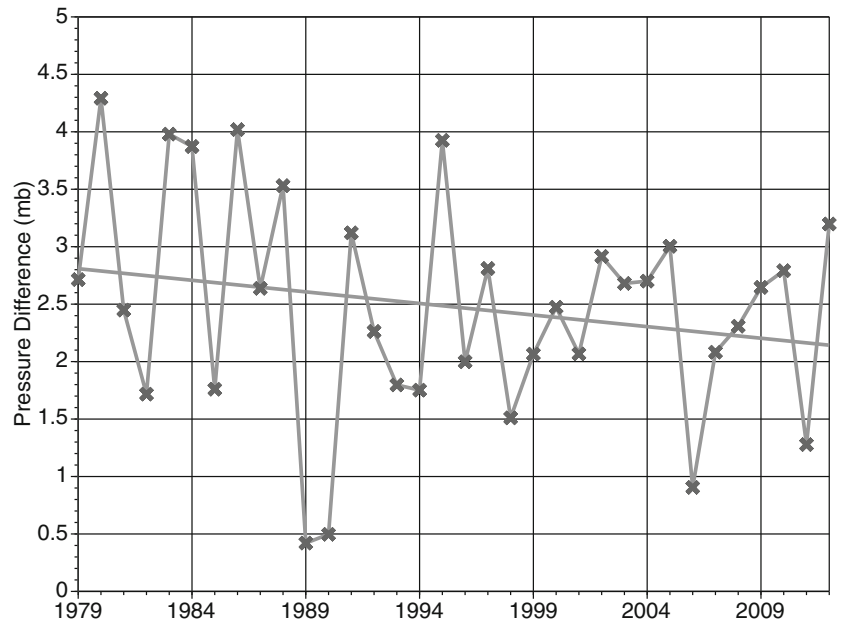

Fig. 7 Atmospheric pressure gradient for a roughly north-south transect between Nome and Cold Bay 


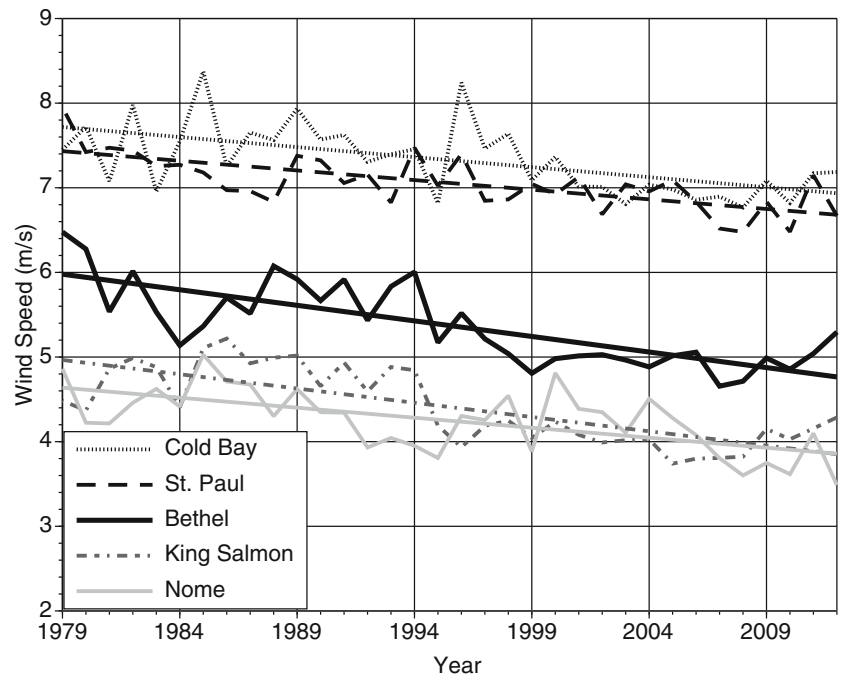

Fig. 8 Trend of mean annual wind speeds for five coastal stations for the study period

confidence level, was calculated. The large range of temperatures from year to year is remarkable, varying up to $10^{\circ} \mathrm{C}$, an extremely high value for a maritime station, and a reflection of the effect of the sea ice surrounding the station.

While the temperature/sea-ice relationship is weaker for the southern part of the Bering Sea, it improved substantially in the later season (January-April); however, the relationship is not as tight as for Nome. St. Paul Island demonstrates well this relationship (not shown).

Mantua et al. (1997) were the first to show the strong influence of the phase of the Pacific Decadal Oscillation (PDO) on the climate of Alaska by examining the relationship between climate variability and salmon production in Alaska and the US Pacific Northwest. Monthly anomalies in the sea surface temperature (SST) field of the North Pacific, poleward of $20^{\circ} \mathrm{N}$, constitute the basis of the PDO index. Other studies of the PDO, with emphasis on its effect on Alaska, were carried out by Papineau (2001) and Hartmann and Wendler (2005). The latter studies showed clearly that in 1976/1977, when the PDO value changed from dominantly negative to dominantly positive values, a sudden temperature increase across Alaska was observed. Hence, it became natural to review the PDO for the time period of the sea ice observation. In Fig. 5, we plotted a time series of the PDO index and indeed a mean decrease in the index from 1.0 to -0.6 could be observed, with large variations from year to year.

In Fig. 2, we presented the mean annual sea ice extent, which showed a slight increase. When correlating these values with the PDO, a correlation coefficient of -0.41 was calculated (not shown). We looked also at the multivariate ENSO Index, which is dependent on the $\mathrm{E}-\mathrm{W}$ pressure gradient in the tropics and influences the SST in the North Pacific. However, the correlation
Fig. 9 Differences in the $1,000 \mathrm{mb}$ geopotential heights for five (1992, 1999, 2008, 2009, and 2012) heavy sea ice years and five $(1979,1989$, 1996, 2003, 2004) light sea ice years based on the NCEP/NCAR reanalysis of the Bering Sea and Alaska. Image provided by the NOAA/ESRL Physical Sciences Division, Boulder Colorado from their Web site at http://www.esrl. noaa.gov/psd/
NCEP/NCAR Reanalysis

$1000 \mathrm{mb}$ Geopotential Height $(\mathrm{m})$ Composite Anomaly 1981-2010 climo

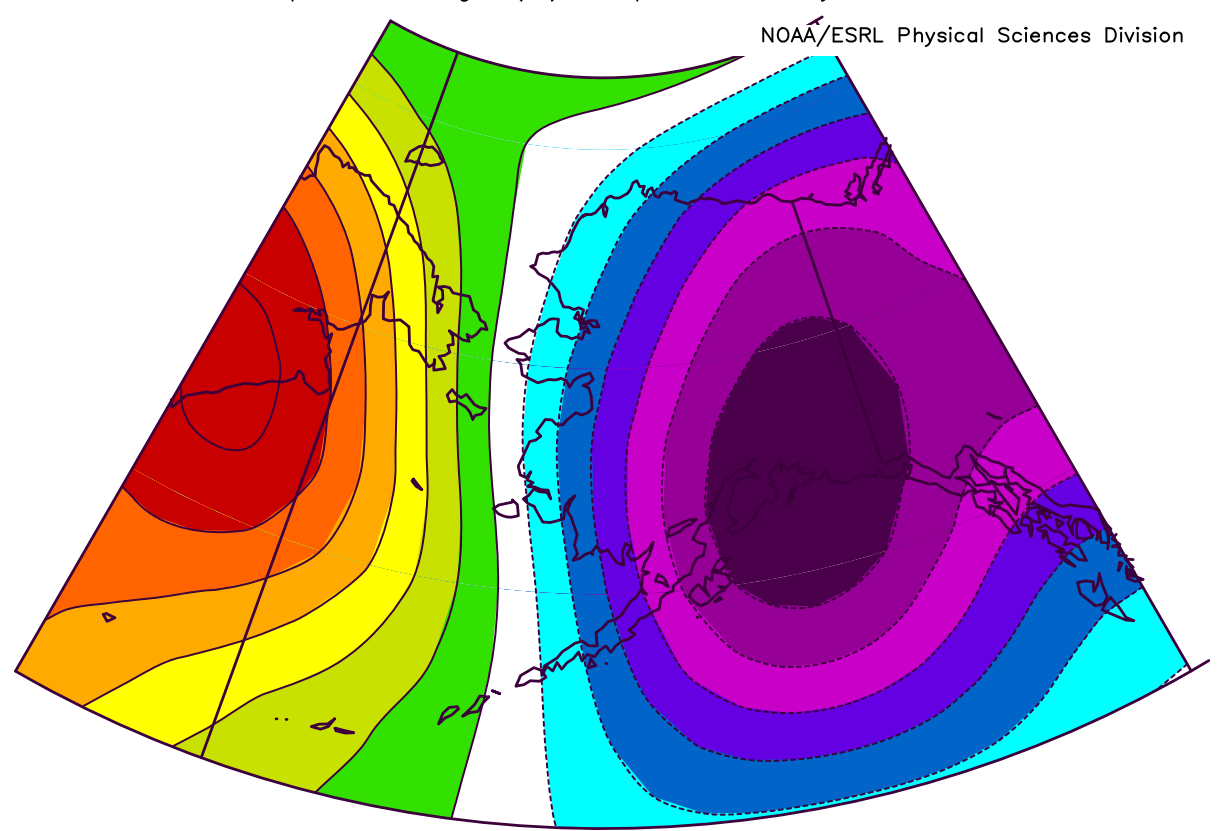

Jan to Dec: : 1992,1999,2008,2009,2012 minus $1979,1989,1996,2003,2004$

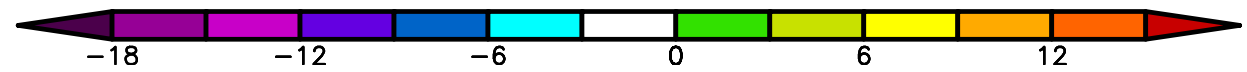


coefficient between ENSO the sea ice extent in the Bering Sea was weak $(r=-0.08)$.

The decreasing PDO numbers (Fig. 5) indicate a cooling of the North Pacific waters. Such cooling will weaken the semipermanent Aleutian Low (Overland et al. 1999; Rodionov et al. 2007; Wendler et al. 2012). We wanted to test this hypothesis with surface observations. There is one station (Cold Bay) close to the center of the Aleutian Low; the geographic location can be seen from see Fig. 1. Looking at the mean annual atmospheric pressure for Cold Bay (Fig. 6), large variations from year to year can be observed. However, the overall trend is positive, an indication of a weakening of the Aleutian Low.

We wanted to test that this trend of atmospheric pressure is not widespread. Hence, we calculated the surface pressure gradient over a distance of some $1,000 \mathrm{~km}$ in the north-south direction from Nome to Cold Bay. Again, while large variations in the pressure differences were observed from year to year, the overall gradient in the atmospheric pressure across this transect is decreasing as can be seen in Fig. 7.

The decreasing atmospheric pressure difference should cause less advection of relatively warm air from the Aleutians into the Northern Bering Sea, where it is much colder. This change could explain the increasing sea ice cover in the Bering Sea. Hence, we looked at the observed wind speeds of four coastal stations (King Salmon, Cold Bay, Nome, and Kotzebue) and one island station located at St. Paul, part of the Pribilof Island group in the Bering Sea. For all five stations, the trend of the mean annual wind speed is presented (Fig. 8), and as expected, a steady decrease in wind speed is observed across the region.

Finally, we looked at the National Centers for Environmental Prediction (NCEP)/National Center for Atmospheric Research (NCAR) reanalyzed dataset (Kalnay 1996). We used annual values and calculated the differences between 5 years with extensive sea ice in the Bering Sea and 5 years with light sea ice. In Fig. 9, the resulting difference map is presented. The figure shows that for years with large ice extent, the atmospheric pressure over the mainland of Alaska decreases, while it increases over Eastern Siberia. This results in an additional northerly wind vector for years with heavy sea ice, which will not only push the sea ice more southerly, but will also advect sea ice from the Chukchi Sea, through the Bering Strait and into the Bering Sea.

\section{Conclusion}

The sea ice cover of the Bering Sea has increased slightly over the last decades, which is in strong contrast to the Arctic Ocean, where a substantial decrease in sea ice has been observed, accompanied by higher temperatures. We offered as explanation the shift in the PDO index, which went to more negative values, bringing colder temperatures to Alaska
(Wendler et al. 2012). This decrease in temperature was especially pronounced in Western Alaska (Overland et al. 2012), which lead to a weakening of the semipermanent Aleutian Low. Hence, less warm air from the South is advected into the Bering Sea region. Both, NCEP/NCAR reanalyzed data as well surface observations from existing stations agree with these assumptions.

Acknowledgments We are thankful for financial support given by Dr. Mark Myers, Vice Chancellor of Research, and by Dr. Robert McCoy, Director, Geophysical Institute, for State of Alaska funds designated for ACRC. Further, John Walsh, William Chapman, Peter Bieniek, and Kevin Galloway helped us in various ways improving the manuscript.

Open Access This article is distributed under the terms of the Creative Commons Attribution License which permits any use, distribution, and reproduction in any medium, provided the original author(s) and the source are credited.

\section{References}

Benner D (1996) NIC Arctic and Antarctic sea ice data. Boulder, Colorado, National Snow and Ice Data Center. Digital media

Bridgman H, Oliver J (2006) The global climate system. Cambridge University Press, Cambridge, p 350pp

Cavalieri D, Parkinson C, Gloersen P, Zwally HJ (2006) Sea ice concentrations from Nimbus-7 SMMR and DMSP SSM/I passivemicrowave data, [updated from 1996]. National Snow and Ice Data Center. Boulder, Colorado, Digital media

Chapman W, Walsh J (1993) Recent variations in sea ice and air temperature at high latitudes. BAMS 74:33-48

Danielson S, Curchitser E, Hedstrom K, Weingartner T, Stabeno P (2011) On ocean and sea ice modes of variability in the Bering Sea. JGR Ocean 116:C12

Fetterer F ed. (2006). A selection of documentation related to National Ice Center Sea Ice Charts in Digital Format. NSIDC Special Report 13. Boulder, CO, USA

Hartmann B, Wendler G (2005) The significance of the 1976 Pacific climate shift on the climatology of Alaska. J Climate 18:4824-4839

Kalnay E (1996) The NCEP/NCAR reanalysis 40-year project. Bull Amer Meteor Soc 77:437-471

Mantua N, Hare S, Zhang Y, Wallace J, Francis R (1997) A pacific interdecadal climate oscillation with impacts on salmon production. BAMS 78:1069-1079

Maslanik J, Serreze M, Agnew T (1999) On the record reduction in Western Arctic Sea ice cover in 1998. Geophys Res Letters 26:1905-1908

Nghiem S, Rigor R, Perovich D, Clemente-Colon P, Wetherly J, Neumann G (2007) Rapid reduction of Arctic perennial sea ice. JGR Letter 34, GL031480

Overland J, Adams J, Bond N (1999) Decadal variability of the Aleutian Low and its relation to high-latitude circulation. J Climate 12(5):1542-1548

Overland J, Wang M, Wood K, Percival D, Bond N (2012) Recent Bering Sea warm and cold events in a 95-year context. Deep-Sea Res II: 6-13

Papineau J (2001) Wintertime temperatures. Int J Climatol 21:1577-1592

Rigor I, Wallace J (2004) Variation in the age of Arctic sea ice and summer sea ice extent. JGR Letter 31, GL019492

Rodionov S, Bond N, Overland J (2007) The Aleution Low. Storm tracks, and winter climate variability in the Bering Sea. Deep Sea Research II 54:2560-2577

Serreze M, Barry R (2006) The Arctic climate system. Cambridge University Press, Cambridge, p 402pp 
Serreze M, Holland M, Stroeve J (2007) Perspectives on the Arctic's shrinking sea-ice cover. Science 315:1533-1536

Walsh J, Chapman W (1990) Short-term climatic variability of the Arctic. J Climate 3(2):237-250

Walsh J, Tanaka H, Weller G (1996) Wadati conference on global change and the polar climate. BAMS 77:237-250

Wendler G, Shulski M, Moore B (2010) Changes in the climate of the Alaskan North Slope and the ice concentration in the adjacent Beaufort Sea. Theor Appl Climatol 99:67-74
Wendler G, Chen L, Moore B (2012) The first decade on the new century: a cooling trend for most of Alaska. The Open Atmospheric Science Journal 6:111-116

Zhang J, Hibler W III (1991) On the role of ocean circulation in seasonal and inter-annual ice-edge variations in the Bering Sea. Annals Glaciology 15:37-44

Zhang J, Woodgate R, Moritz R (2010) On ocean and sea ice modes of variability in the Bering Sea. JGR Ocean 40:1729 1747 